\title{
A Novel Monoclonal Antibody for RAGE-Directed Imaging Identifies Accelerated Atherosclerosis in Diabetes
}

Yared Tekabe ${ }^{1}$, Joane Luma ${ }^{1}$, Andrew J. Einstein ${ }^{1}$, Marija Sedlar ${ }^{1}$, Qing Li ${ }^{2}$, Ann Marie Schmidt ${ }^{2}$, and Lynne L. Johnson ${ }^{1}$

${ }^{I}$ Division of Cardiology, Department of Medicine, Columbia University Medical Center, New York, New York; and ${ }^{2}$ Division of Surgical Science, Department of Surgery, Columbia University Medical Center, New York, New York

Receptor for advanced glycation end products (RAGE) binds advanced glycation end products and other inflammatory ligands and is expressed in atherosclerotic plaques in diabetic and nondiabetic subjects. The higher expression in diabetes mellitus corresponds to the accelerated course of the atherosclerosis. This study was designed to test the hypothesis that the level of RAGE expression in atherosclerosis can be detected by quantitative in vivo SPECT and that counts in the target will correlate with the strength of the biologic signal. Methods: A monoclonal murine antibody was developed against the V-domain of RAGE,

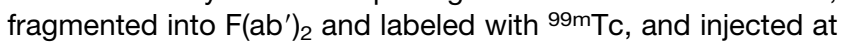
a dose of $15.14 \pm 1.23 \mathrm{MBq}$ into 24-wk-old male apolipoprotein E null $\left(\mathrm{ApoE}^{-/-}\right)$mice $(n=22)$, including mice with streptozotocin-induced diabetes mellitus $(n=8)$, nondiabetic mice $(n=8)$, and control ApoE ${ }^{-1-} / \mathrm{RAGE}^{-/-}$double-knock-out mice $(n=6)$. Four hours later (allowing for blood-pool clearance), the mice were imaged and sacrificed, and the proximal aorta was removed and counted to calculate the percentage injected dose of RAGE per gram of tissue, followed by histologic and immunohistochemical characterization. Results: Radiotracer uptake in the aortic lesions was clearly visualized noninvasively by SPECT. RAGE uptake as percentage injected dose in diabetic ApoE ${ }^{-1-}$ mice $\left(1.39 \pm 0.16 \times 10^{-2}\right)$ was significantly higher than that in nondiabetic $\mathrm{ApoE}^{-1-}$ mice $\left(0.48 \pm 0.27 \times 10^{-2}\right)(P<0.0001)$. The radiotracer uptake was highly correlated with RAGE expression by quantitative immunohistomorphometry $(r=0.82, P=$ $0.002)$ and with percentage of macrophages $(r=0.86, P<$ 0.0001). Conclusion: In this study, 99mTc-labeled anti-RAGE $\mathrm{F}\left(\mathrm{ab} \mathrm{b}^{\prime}\right)_{2}$ SPECT successfully identified early accelerated disease in diabetes mellitus for age-matched $\mathrm{ApoE}^{-1-}$ mice and quantified RAGE expression over a range of lesion severities.

Key Words: $\mathrm{ApoE}^{-1-}$ mice; atherosclerosis; diabetes; RAGE

J Nucl Med 2010; 51:92-97

DOI: 10.2967/jnumed.109.064659

Received Mar. 30, 2009; revision accepted Sep. 5, 2009.

For correspondence or reprints contact: Yared Tekabe, Division of Cardiology, Department of Medicine, Columbia University Medical

Center, 620 W. 168 St., New York, NY 10032.

E-mail: yt2166@columbia.edu

COPYRIGHT $\odot 2010$ by the Society of Nuclear Medicine, Inc.
D iabetes has become a worldwide epidemic and is a major risk factor for coronary artery disease. Atherosclerosis in diabetic patients takes an accelerated course. Assessing total plaque burden is important in tailoring individual patient therapy. Advances in molecular biology over the past 10 years have identified potential sites in atherosclerotic plaque that can be targeted with probes producing signals that can be detected by external imaging. Experimental and clinical studies have reported the feasibility of detecting signals from atherosclerotic plaque using probes in nanomolar concentrations. Targets below the resolution of imaging devices can be detected as beacons if there are abundant binding sites and low background activity.

Receptor for advanced glycation end products (RAGE) is a member of an immunoglobulin superfamily expressed at low levels in adult tissues in homeostasis but highly expressed in atherosclerotic lesions (1-3). RAGE was initially identified and characterized as the cellular binding and interaction site for advanced glycation end products (AGEs) resulting from glycation or oxidation of proteins and lipids during normal aging and from the accelerated degree of hyperglycemia in diabetes $(4,5)$. The ligandenriched environment in diabetes increases the expression of RAGE. Binding of AGEs to RAGE induces multiple signaling pathways involved in plaque progression and inflammation. These receptors also bind the non-AGErelated proinflammatory markers S100/calgranulins, amphoterins, and extracellular newly identified RAGE-binding protein $(6,7)$. Administration of RAGE antagonists to diabetic apolipoprotein $\mathrm{E}$ null $\left(\mathrm{ApoE}^{-/-}\right)$mice attenuates vascular injury and greatly attenuates the initiation and acceleration of atherosclerosis $(8,9)$. These findings show that RAGE expression is greater in diabetic than nondiabetic atherosclerosis and plays an important role in accelerating the disease in diabetes.

In a proof-of-concept paper, we showed the ability to visualize uptake of an $\mathrm{F}\left(\mathrm{ab}^{\prime}\right)_{2}$ fragment of a ${ }^{99 \mathrm{~m}} \mathrm{Tc}$-labeled polyclonal antibody in atherosclerotic plaque in the prox- 
imal aortae of 20-wk-old nondiabetic $\mathrm{ApoE}^{-/-}$mice using planar imaging (10). The generation of monoclonal antibodies is now a standard and increasingly routine procedure. Because the hybridoma cell lines are immortal, there is an unlimited source of the monoclonal antibody. Compared with polyclonal antibodies, monoclonal antibodies show reduced nonspecific binding and reduced nonspecific background activity, and we therefore developed a monoclonal antibody directed against the same peptide sequence on the extracellular receptor domain of RAGE. The hypothesis of the present study was that in agematched $\mathrm{ApoE}^{-1-}$ mice, uptake of a radiolabeled fragment of the monoclonal anti-RAGE antibody would be greater in diabetic than nondiabetic mice and would be a marker of the accelerated course of atherosclerosis in these diabetic animals.

\section{MATERIALS AND METHODS}

\section{Experimental Model}

All animal experiments were performed with the approval of the Institutional Animal Care and Use Committee of Columbia University. Male ApoE ${ }^{-1-}$ mice that backcrossed more than 10 generations in the C57BL/6 background were obtained (Jackson Laboratories). The $\mathrm{RAGE}^{-1-} / \mathrm{ApoE}^{-1-}$ mice $(n=6)$ were generated by backcrossing $\mathrm{RAGE}^{-1-}$ mice on the $\mathrm{C} 57 \mathrm{BL} / 6$ background into $\mathrm{ApoE}^{-/-}$mice on the same background for 10 generations (11). At age $6 \mathrm{wk}, \operatorname{ApoE}^{-1-}$ mice $(n=8)$ were made diabetic via 5 daily intraperitoneal injection of streptozotocin (Sigma), $50 \mathrm{mg} / \mathrm{kg}$ in citrate buffer $(0.05 \mathrm{~mol} / \mathrm{L}, \mathrm{pH} 4.5)$, resulting in insulin deficiency (12). Control $\mathrm{ApoE}^{-1-}$ mice $(n=8)$ received citrate buffer only. All animals were studied at age 24 wk.

\section{Development of Monoclonal Anti-RAGE Antibody}

We developed a novel antibody in rabbits against the V-domain of RAGE designed to display immunoreactivity in mice, pigs, and humans. Based on Genbank sequences of human, murine, and porcine RAGE, the following sequence alignment was determined and peptide prepared (13): human, 103-NRNGKETKSNYRVRVYQIP121; murine, 102-NRRGKEVKSNYRVRVYQIP-120; and peptide, 1-NRRGKEVKSNYRVRVYQIC-19.

For hybridoma development, $20 \mathrm{mg}$ of the peptide AcNRRGKEVKSNYRVRVYQIC-amide was produced (Quality Controlled Biochemicals). The peptide was conjugated to carrier molecule keyhole limpet hemocyanin, and $15 \mathrm{BALB} / \mathrm{c}$ mice were immunized with the conjugated peptide (Strategic BioSolution). Test bleeds were obtained to evaluate polyclonal antisera binding by screening enzyme-linked immunosorbent assay. Fusion was successful and supernatants selected to test the hybridomas. The hybridomas were subcloned and the best subclones selected. Monoclonal antibodies were produced in vitro and purified by protein $\mathrm{A}$ and low endotoxin units (less than 3 endotoxin units/mg of purified antibody).

The immunoreactivity of diethylenetriaminepentaacetic acid (DTPA)-modified antibody was tested by enzyme-linked immunosorbent assay using soluble RAGE antigen-coated microtiter plates. Binding of the anti-RAGE $\mathrm{F}\left(\mathrm{ab}^{\prime}\right)_{2}$ to the receptor was compared with that of unmodified anti-RAGE IgG using horseradish peroxidase-conjugated secondary antirabbit IgG. The antibody concentration, which gave $50 \%$ of maximum binding with anti-RAGE $\mathrm{F}\left(\mathrm{ab}^{\prime}\right)_{2}$, was $0.2 \mu \mathrm{g} / \mathrm{mL}$, which is equivalent to $2 \times 10^{-9} \mathrm{~mol} / \mathrm{L}$ or apparent affinity of $0.5 \times 10^{9} \mathrm{~L} / \mathrm{mol}$. The $50 \%$ of maximum binding concentration of unmodified anti-RAGE IgG was $0.4 \mu \mathrm{g} / \mathrm{mL}$, which is equivalent to $2 \times 10^{-9} \mathrm{~mol} / \mathrm{L}$ or apparent affinity of $0.5 \times 10^{9} \mathrm{~L} / \mathrm{mol}$.

\section{Preparation of $\mathbf{F}\left(a b^{\prime}\right)_{2}$ Fragments and Radiolabeling}

$\mathrm{F}\left(\mathrm{ab}^{\prime}\right)_{2}$ fragments of the purified anti-RAGE antibody were prepared as previously described (10). These fragments have more antigen binding sites available than Fab and faster blood-pool and renal clearance than whole antibody. Direct coupling of antiRAGE $\mathrm{F}\left(\mathrm{ab}^{\prime}\right)_{2}$ antibodies to DTPA (Sigma) for ${ }^{99 \mathrm{~m}} \mathrm{Tc}$ labeling was performed as previously described $(10,14)$. The mean specific activity was $6.58 \pm 0.68 \mathrm{MBq} / \mu \mathrm{g}$ of protein, and the mean radiopurity was $98 \% \pm 0.54 \%$ by instant thin-layer chromatography. The mean injected ${ }^{99 \mathrm{~m}} \mathrm{Tc}$ dose was $15.14 \pm 1.23 \mathrm{MBq}$.

For the first 3 mice, serial drops of blood were obtained from tail vein nicking at 5, 10, 30, 60, 120, 180, and $360 \mathrm{~min}$ and $24 \mathrm{~h}$ and counted to measure blood-pool clearance and determine the optimal time for imaging after tracer injection.

\section{SPECT}

Whole-body in vivo SPECT (HiSPECT; BioScan) was performed on all mice $4 \mathrm{~h}$ after injection of radiolabeled anti-RAGE antibody fragment. SPECT images were acquired with specially designed multipinhole collimators with $1.0-\mathrm{mm}$ pinhole tungsten apertures mounted on a triple-detector $\gamma$-camera (Prism 3000XP; Picker). The acquisition was set up for the photopeak for ${ }^{99 m}$ Tc imaging (140 keV, 10\% energy window) with the following parameters: step-and-shoot rotation, $90 \mathrm{~s}$ per stop, $30^{\circ}$ step in $360^{\circ}$ rotation, and $15.3-\mathrm{cm}$ radius of rotation. We acquired images with a $256 \times 256$ matrix and a reconstructed voxel size of $0.125 \mathrm{~mm}^{3}$.

\section{Image Analysis and Ex Vivo Counting}

At the end of imaging, the animals were sacrificed, the organs were removed and weighed, and organ-associated radioactivity was counted in a $\gamma$-counter (Wallac Wizard 1470; PerkinElmer) for determination of the percentage injected dose (\%ID) of radiotracer per gram of tissue. Absolute quantification of the reconstructed SPECT images was performed in Interview XP software (Mediso) using region-of-interest drawings in the transaxial plane. The system is calibrated for absolute quantification using specially designed rat- and mouse-shaped phantoms filled with known levels of ${ }^{99 \mathrm{~m}} \mathrm{Tc}$ imaged with the same protocol used for the animal studies. This quantification technique has been shown to be better than $4 \%$ accurate when performed with the same methodology (HiSPECT and Mediso software) on a comparable imaging system (15). The quantitative uptake in the aorta, in megabecquerels, was divided by total injected dose to obtain \%ID.

\section{Histology}

The proximal aortae were harvested by perfusion fixation for 10 min with $10 \%$ neutral buffered formalin. Tissues were fixed for $24 \mathrm{~h}$ in $10 \%$ formalin, followed by paraffin embedding. A $400-\mu \mathrm{m}$ section of the proximal aorta from the aortic valve leaflets was excised. Serial $5-\mu m$-thick sections were cut and stained with hematoxylin-eosin for morphology and for immunohistochemistry.

For cellular characterization of atherosclerotic lesions, immunohistochemical staining was performed as previously described (10). Briefly, tissue sections were deparaffinized in xylene, and endogenous peroxidase activity was blocked using $0.3 \%$ hydrogen 
A
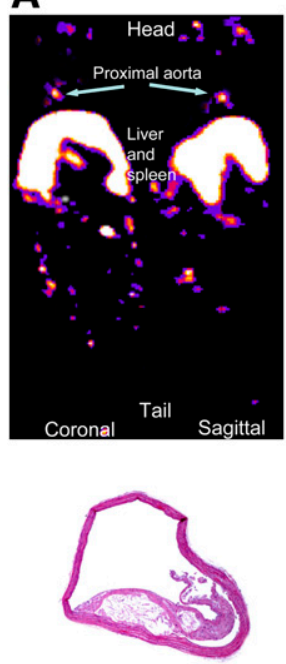

B

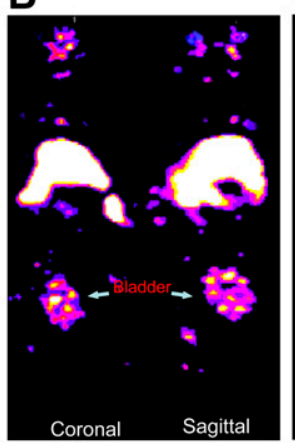
$F\left(a b^{\prime}\right)_{2}$. Corresponding lesion severity is shown by hematoxylin-eosin staining of proximal aortic section (bottom). Diabetic $\mathrm{ApoE}^{-1-}$ mice showed more intense tracer accumulation in thorax, compared with uptake in nondiabetic $\mathrm{ApoE}^{-/-}$mice. Controls showed no localization of radiotracer at target.

FIGURE 1. Representative sagittal coronal SPECT images obtained diabetic $\mathrm{ApoE}^{-/-}$mouse $(\mathrm{B})$, and control ApoE ${ }^{-/-} / \mathrm{RAGE}^{-1-}$ mouse (C) $4 \mathrm{~h}$ after injection of anti-RAGE $\mathrm{F}\left(\mathrm{ab}^{\prime}\right)_{2}$ and from nondiabetic $\mathrm{ApoE}^{-/-}$mouse injected with control nonspecific IgG peroxide. Tissue sections were then incubated in protein-free block (Dako) for $10 \mathrm{~min}$ to inhibit the nonspecific binding of primary antibody. Staining for RAGE was performed using antibody against RAGE $(50 \mu \mathrm{g} / \mathrm{mL})$. Macrophages were identified using the marker Mac-3 (1:20; BD Pharmingen). Smooth muscle cells were identified using a primary antibody HHF-35 against $\alpha$-actin (1:250; Sigma). Control immunostaining was performed using the respective nonspecific IgG. Detection was performed with horseradish peroxidase-conjugated respective secondary antibody. Color was developed with $3^{\prime}, 3^{\prime}$-diaminobenzidine (DAB substrate kit; Vector Laboratories) and counterstaining with the Gill hematoxylin solution. Slides were photographed and saved as digital files.

Morphometric analyses of the arterial segments were performed using a Nikon microscope and Image Pro Plus software (Media Cybernetics Inc.). The amount of aortic lesion formation in each animal was measured as percentage lesion area per total area of the aorta (16). Cells staining positively for a particular chromogen were identified using a color recognition method, and the number of nuclei from positively staining cells was divided by the total number of cells in the tissue cross section.

Dual-label confocal microscopy studies were performed to determine the cell types expressing RAGE in atherosclerotic lesions. Aortic sections were subjected to immunofluorescent colocalization of RAGE with macrophages and smooth muscle cells by overnight incubation at $4{ }^{\circ} \mathrm{C}$ with the respective antisera as described above. The sections were then incubated with fluorescent conjugated secondary antibodies (Texas Red antirabbit, fluorescein isothiocyanate antimouse and antirat; Vector Laboratories) at 1:200 at $4^{\circ} \mathrm{C}$ for $2 \mathrm{~h}$. When the Texas Red and fluorescein isothiocyanate signals colocalize, a yellow signal is seen.

\section{Statistical Analysis}

Continuous variables were expressed as mean \pm SD. Normality was assessed using the Sharpiro-Wilk W test. Equality of variances was assessed using the Levene test. Groups were compared using the Student $t$ test or the Mann-Whitney $U$ test, as appropriate. Correlation was assessed using the Pearson productmoment correlation coefficient. All statistical tests were 2-tailed, with a $P$ value of less than 0.05 denoting significance. All statistical analyses were performed using STATA 10.1 (StataCorp).
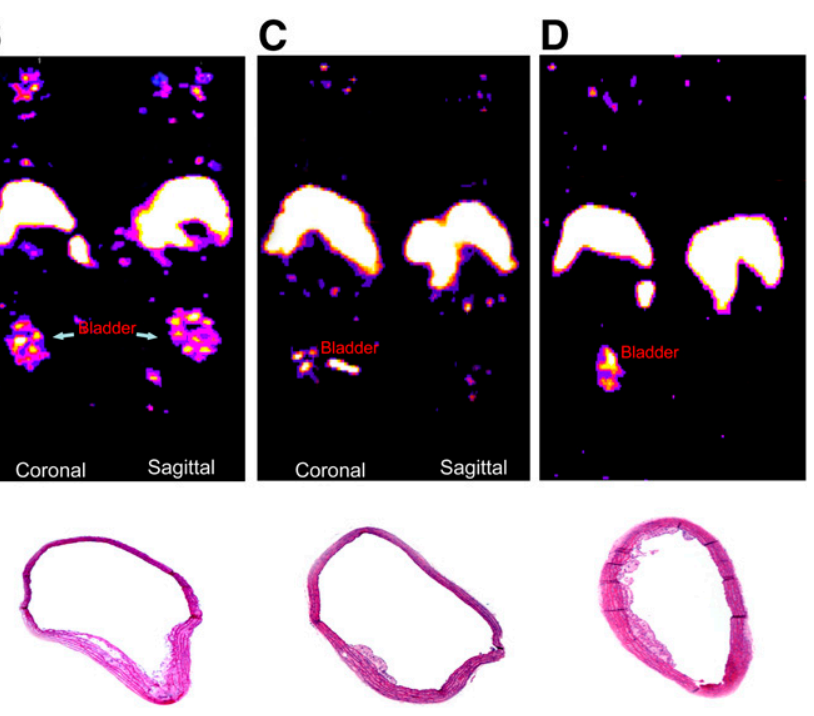

\section{RESULTS}

\section{Blood-Pool Clearance}

Blood-pool clearance of the ${ }^{99 \mathrm{~m}}$ Tc-labeled monoclonal $\mathrm{F}\left(\mathrm{ab}^{\prime}\right)_{2}$ was measured, to determine the optimal time for imaging. The clearance is biexponential, with the half-time equal to $20 \mathrm{~min}$ for the first (fast) component and $7 \mathrm{~h}$ for the second (slower) component. From these data, we determined that the optimal time for imaging is $4 \mathrm{~h}$ after tracer injection.

\section{Detection of RAGE in Atherosclerotic Plaques}

In vivo imaging of diabetic ApoE ${ }^{-1-}$ mice showed focal accumulation of the tracer in the thorax corresponding to the location of the proximal aortic atherosclerotic lesion. An example from one experiment is shown in Figure 1A. The nondiabetic ApoE $\mathrm{E}^{-/-}$mice also showed tracer uptake in the thorax corresponding to the proximal aorta, but the uptake was less intense (Fig. 1B). Control $\mathrm{ApoE}^{-/-}$/ $\mathrm{RAGE}^{-1-}$ mice showed no uptake of the radiotracer in the aortic region of the thorax, and histologic examination of the aorta revealed minimal lesions (Fig. 1C). Atherosclerotic $\mathrm{ApoE}^{-/-}$mice injected with a control-irrelevant ${ }^{99 m}$ Tc-DTPA-labeled antibody fragment-showed no tracer uptake in the thorax although the in situ dissection of the aortic arch showed extensive atherosclerotic plaque (Fig. 1D). From regions of interest drawn on the scans around the focal uptake in the thorax, uptake in the diabetic ApoE ${ }^{-1-}$ group $\left(1.39 \pm 0.16 \times 10^{-2} \%\right.$ ID) was significantly greater than that in corresponding locations in the nondiabetic ApoE ${ }^{-1-}$ group $\left(0.48 \pm 0.27 \times 10^{-2} ; P<\right.$ $0.0001)$.

We confirmed tracer uptake in the proximal aorta by ex vivo radioactivity counting of aortic tissues. There was a significant difference between the diabetic and nondiabetic ApoE ${ }^{-/-}$mice $(0.36 \pm 0.19$ vs. $0.052 \pm 0.028 \% \mathrm{ID} / \mathrm{g} ; P=$ 0.002) (Fig. 2). The radiotracer uptake in the aorta of nondiabetic mice was greater than in $\mathrm{ApoE}^{-/-} / \mathrm{RAGE}^{-/-}$ 


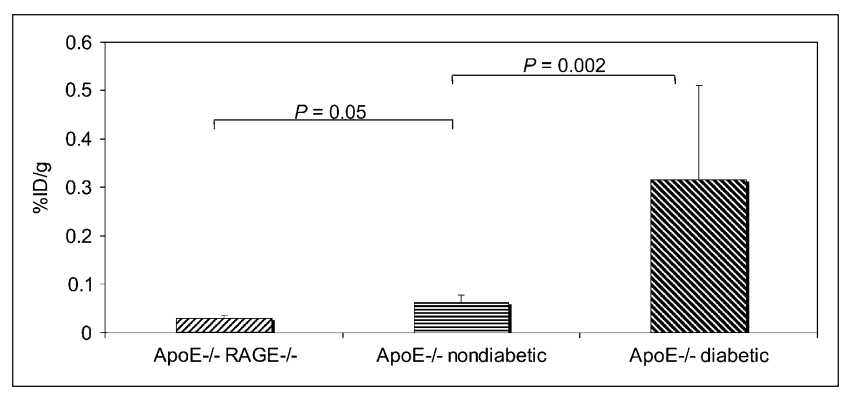

FIGURE 2. Comparison of $99 \mathrm{mTc}$-labeled anti-RAGE $\left.\mathrm{F}(\mathrm{ab})_{2}\right)_{2}(\% \mathrm{ID} / \mathrm{g})$ in proximal aorta of control $\mathrm{ApoE}^{-1-}$ mice, non-diabetic ApoE ${ }^{-1-}$ mice, and diabetic $\mathrm{ApoE}^{-1-}$ mice at 5-6 $\mathrm{h}$ after injection ( $n=6-8$ animals per group; bars represent mean $\pm \mathrm{SD}$ ).

mice, but the significance was borderline $(P=0.05)$ by 2-tailed testing.

Biodistribution studies of radiolabeled anti-RAGE F $\left(\mathrm{ab}^{\prime}\right)_{2}$ in nontarget organs of diabetic and nondiabetic mice were performed (Fig. 3). The highest radiotracer uptake in both groups was in the liver and spleen.

\section{Histologic Characterization of Atherosclerotic Lesions}

Aortic sections from diabetic $\mathrm{ApoE}^{-1-}$ mice showed mainly American Heart Association class III lesions, whereas nondiabetic mice showed mainly American Heart Association class II lesions. The mean cross-sectional area of the aortic lesions, expressed as percentage lesion area of total aortic area, was $37.1 \% \pm 16.1 \%$ (range, $16.4 \%-66.5 \%$ ) in diabetic $\mathrm{ApoE}^{-1-}$ mice and $20.7 \% \pm 9.5 \%$ (range, 8.9$33.5)$ in nondiabetic $\mathrm{ApoE}^{-1-}$ mice $(P=0.04)$.

Immunohistochemical staining of the proximal aorta identified higher expressions of macrophages and RAGE in diabetic $\mathrm{ApoE}^{-1-}$ mice than in nondiabetic mice (Fig. 4A). Total RAGE and macrophage burden in the atherosclerotic lesions was quantified. The percentage of RAGEpositive cells in the lesions in diabetic $\mathrm{ApoE}^{-/-}$mice

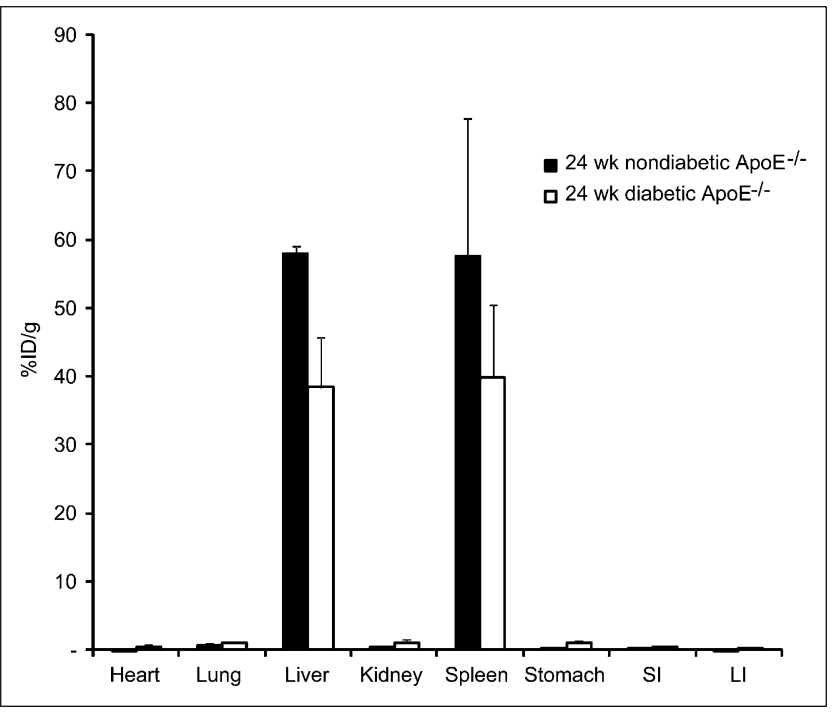

FIGURE 3. Biodistribution of $99 \mathrm{~m}$ Tc-labeled anti-RAGE $\left.\mathrm{F}(\mathrm{ab})_{2}\right)_{2}(\% \mathrm{ID} / \mathrm{g})$ in nontarget organs of diabetic ApoE ${ }^{-1-}$ mice and nondiabetic ApoE ${ }^{-/-}$mice at 5-6 h after injection $(n=6-8$ animals per group; bars represent mean $\pm \mathrm{SD}$ ). $\mathrm{SI}=$ small intestine; $\mathrm{LI}=$ large intestine.

$(37.7 \% \pm 6.9 \%)$ was increased more than 2 -fold over the percentage in nondiabetic mice $(15.9 \% \pm 4.7 \%, P=$ 0.0008). Similarly, total macrophage burden was significantly increased in the lesions in diabetic mice $(28.2 \% \pm$ $7.6 \%)$, compared with nondiabetic mice $(13.4 \% \pm 4.8 \%$, $P=0.0004)$. The specificity of anti-RAGE antibody was confirmed by lack of staining of aortic lesions in control $\mathrm{ApoE}^{-1-} / \mathrm{RAGE}^{-1-}$ mice (Fig. 4B). Dual immunofluorescent staining for RAGE-expressing cells showed RAGE to colocalize predominantly with macrophages (Fig. 5).

\section{Quantitative In Vivo RAGE Uptake Versus Quantitative Histomorphometry}

For regression analysis, we plotted individual values for radiotracer uptake in the proximal aorta against percentages
A

Nondiabetic apo $\mathrm{E}^{-1}$
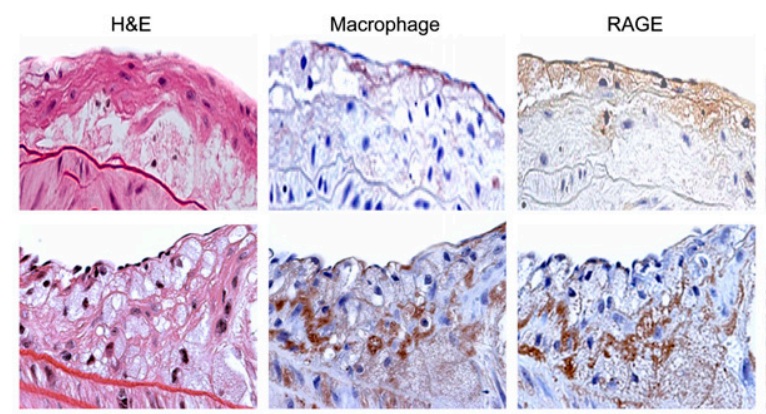

B

ApoE $\%$ IRAGE $^{-1}$

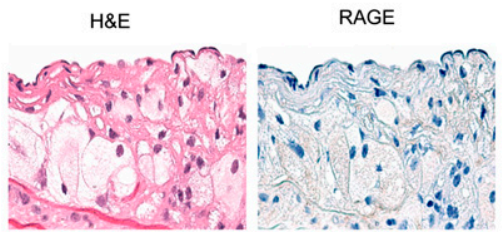

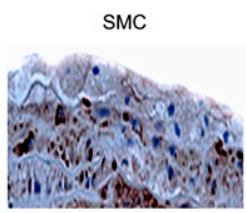

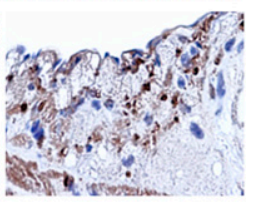
cle cells was higher in diabetic $\mathrm{ApoE}^{-/-}$ mice (top) than in nondiabetic mice (bottom). (B) Specificity of anti-RAGE antibody was confirmed by lack of staining of aortic lesions in control $\mathrm{ApoE}^{-/-} / \mathrm{RAGE}^{-/-}$mice. Chromogen stains brown. $(\times 400)$ 

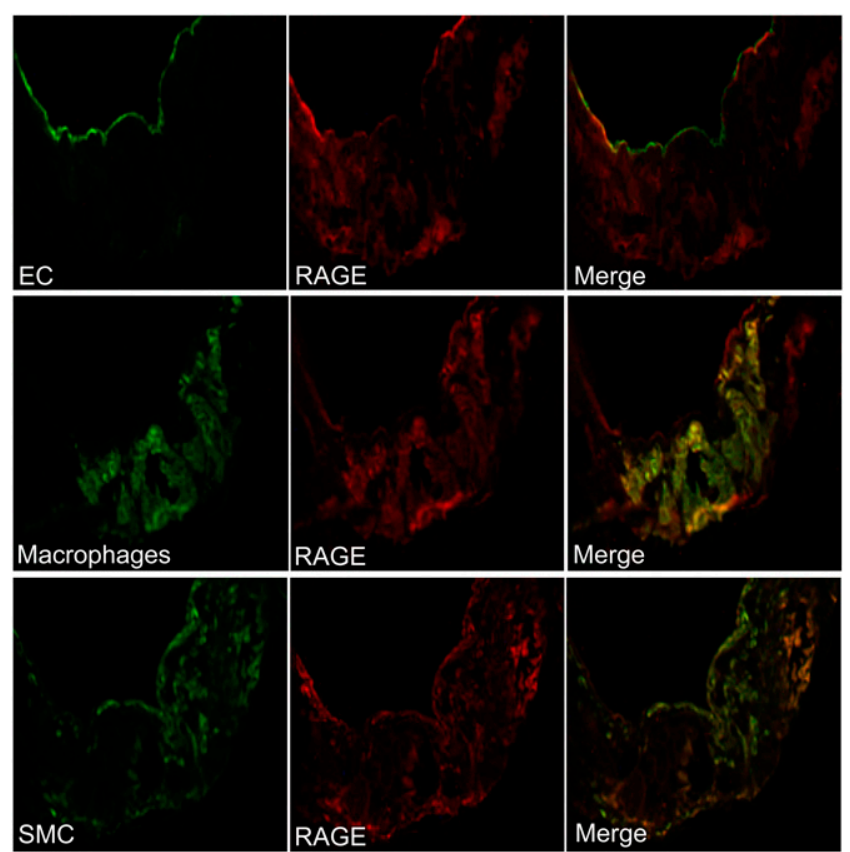

FIGURE 5. Immunofluorescence double staining for cells expressing RAGE in aortic lesion in $\mathrm{ApoE}^{-/-}$mouse. Shown is confocal microscopy of serial sections double-immunofluorescently labeled for RAGE (anti-RAGE, Texas Red), for endothelial cells (FVIII, fluorescein isothiocyanate), for smooth muscle cells ( $\alpha$-actin, fluorescein isothiocyanate), and for macrophages (Mac-3, fluorescein isothiocyanate). Areas in yellow represent colocalization. SMC = smooth muscle cell; $E C=$ endothelial cells. $(\times 200)$

of RAGE-positive cells and macrophage-positive cells. Radiotracer uptake correlated strongly with RAGE expression ( $r=0.82, P=0.002)$ (Fig. 6A) and with macrophages $(r=0.86, P<0.0001)$ (Fig. 6B). There was also a significant positive correlation between radiotracer uptake in the proximal aorta from scans and ex vivo radioactivity counts of the proximal aorta $(r=0.82, P=$ 0.0001).

\section{DISCUSSION}

The report describes follow-up data of a previously published proof-of-concept study with a polyclonal antiRAGE antibody. We subsequently developed a novel monoclonal antibody directed against the V-domain of RAGE designed to display immunoreactivity in mice, pigs, and humans and radiolabel the $\mathrm{F}\left(\mathrm{ab}^{\prime}\right)_{2}$ fragments. This present study compared uptake of the monoclonal antibody in atherosclerotic lesions of the proximal aorta in $\mathrm{ApoE}^{-1-}$ mice with and without diabetes. The quantitative uptake of radioactivity in the target lesion correlated both with RAGE expression and with macrophages by quantitative histomorphometry.

Progress in the field of vascular biology coupled with pathologic studies of human autopsy material has delineated the course of plaque evolution and signals of plaque vulnerability. The latter include increased lesional macrophages indicating inflammation, apoptosis of macrophages in the shoulder regions of thin-cap fibroatheromas, and activation of metalloproteinases in the connective tissue of plaques (11). Imaging studies have targeted inflammation with ${ }^{18}$ F-FDG (17), apoptosis in the plaque with annexin-V (18), and metalloproteinase expression with radiolabeled broad-based matrix metalloproteinase inhibitor (19). This study extended targeted imaging of atherosclerosis to imaging RAGE.

Binding of AGEs to RAGE induces multiple signaling pathways involved in plaque progression. RAGE is highly conserved across species. Several reports using human material have studied RAGE expression in atherosclerotic plaques $(4,5)$. One study used plaques obtained from patients undergoing carotid endarterectomy, and the other used coronary arteries from subjects who had sudden cardiac death. Both studies showed greater immunoreactivity for RAGE in atherosclerotic tissue from diabetic patients than from nondiabetic patients. In addition, there were greater numbers of inflammatory cells (macrophages, $\mathrm{T}$ lymphocytes) in the plaques, and the cells stained positively for RAGE. As a marker of inflammation, RAGE

FIGURE 6. Correlation of macrophage-positive cells (A) and RAGEpositive cells (B) with 99mTc-labeled anti-RAGE $F\left(a b^{\prime}\right)_{2}$ uptake. Regression analysis demonstrates significant association between aortic regions of interest (\%ID) and aortic content of macrophages or RAGE-positive cells from diabetic $(\circlearrowleft)$ and nondiabetic $(\bigcirc)$ $\mathrm{ApoE}^{-/-}$mice.
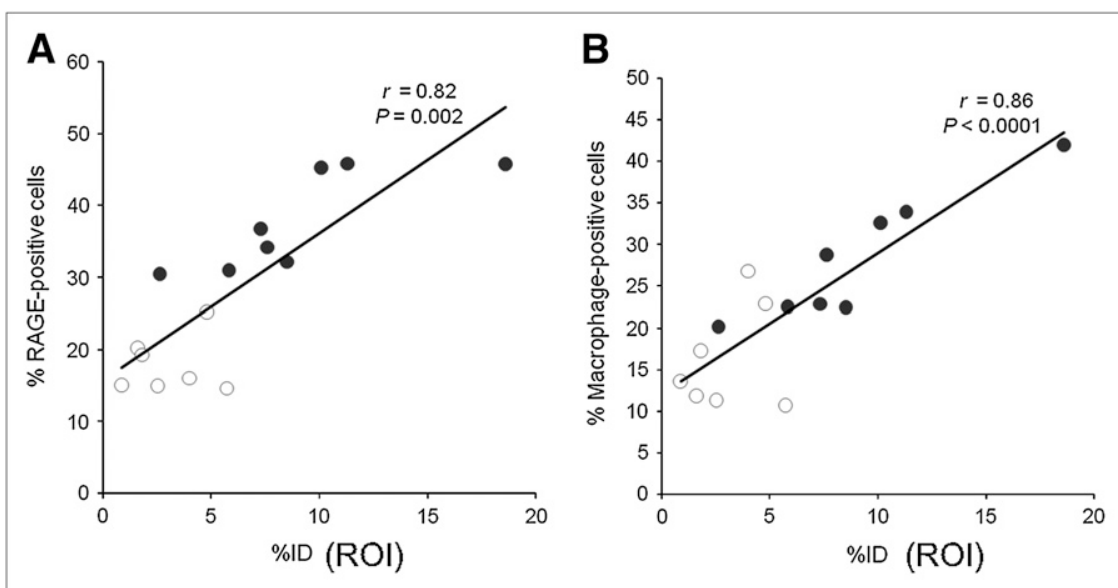
is similar to other targeted radiotracers that colocalize with macrophages. It is unique because it also represents a marker of prolonged hyperglycemia and plays a role in complications of diabetes, including atherosclerosis, limb ischemia, and neurologic disorders.

This study had several limitations: the choice of DTPA as chelator, the relatively large size of the antibody fragment, and the lack of hybrid SPECT/CT. DTPA has proven to be a useful chelator for binding radiotracers to antibody fragments, but the binding kinetics of other chelators such as hydrazinonicotinamide have proven to be superior and are largely replacing DTPA for reliable labeling of proteins with radionuclides. The low \%ID in the aortic lesions could partially be explained by loss of radionuclide signal through dissociation from the antibody fragment. We plan to explore other chemical approaches to labeling the antibody fragment with ${ }^{99 \mathrm{~m}} \mathrm{Tc}$. The slow blood-pool clearance of the $F\left(a b^{\prime}\right)_{2}$ fragment due to its size is a drawback for in vivo imaging. However, for maximal labeling of targets in the vascular wall, there is some advantage to the longer exposure of the receptors to the ligands afforded by residual blood activity. We plan to develop the single-chain variable fragment to the monoclonal anti-RAGE antibody in the hopes that this smaller fragment with more rapid blood-pool clearance will still have an adequate exposure time to the binding sites. Hybrid imaging with SPECT and contrast CT would provide the opportunity to localize the focal uptake of the radiotracer in the thorax to vascular structures. We now have the capability to perform hybrid imaging of atherosclerosis in mice.

\section{CONCLUSION}

In a previous publication, our group documented in vivo uptake of radiolabeled polyclonal anti-RAGE antibodies on planar scans in the proximal aortae of 20-wk-old $\mathrm{ApoE}^{-1-}$ mice fed a Western-type diet. This present report extends our previous work in several important ways. We used a newly developed monoclonal anti-RAGE antibody that shows improved specificity, compared with the polyclonal antibody. We compared uptake in proximal aortic atherosclerotic lesions in $\mathrm{ApoE}^{-1-}$ mice both with and without streptozotocin-induced diabetes. Most importantly, we performed SPECT and correlated the radiotracer uptake in the lesions from the scans with quantitative staining both for RAGE and for macrophages. There were excellent correlations with both variables across a range of lesion sizes and histologic types, including both diabetic and nondiabetic mice. In mice genetically prone to atherosclerosis, ${ }^{99 \mathrm{~m}} \mathrm{Tc}-$ labeled anti-RAGE $\mathrm{F}\left(\mathrm{ab}^{\prime}\right)_{2}$ SPECT identified early accelerated lesions in diabetic, compared with nondiabetic, animals. This technique for in vivo nondestructive quantification of RAGE expression may have applications in assessing novel therapies in experimental animals and possibly in humans.

\section{ACKNOWLEDGMENTS}

We thank Geping Zhang for her assistance with immunohistochemical staining. This work was supported by grants from the American Heart Association Heritage Foundation award and from the American Society of Nuclear Cardiology and the Juvenile Diabetes Research Foundation.

\section{REFERENCES}

1. Kislinger T, Fu C, Huber B, et al. $\mathrm{N}^{\varepsilon}$-(carboxymethyl) lysine adducts of proteins are ligands for receptor for advanced glycation endproducts that activate cell signaling pathways and modulate gene expression. J Biol Chem. 1999;274: 31740-31749

2. Hofmann MA, Drury S, Fu C, et al. RAGE mediates a novel proinflammatory axis: a central cell surface receptor for S100/calgranulin polypeptides. Cell. 1999;97:889-901.

3. Schmidt AM, Yan SD, Brett J, et al. Regulation of human mononuclear phagocyte migration by cell surface binding proteins for AGE. J Clin Invest. 1993;91:2155-2168.

4. Burke AP, Kolodgie FD, Zieske A, et al. Morphologic findings of coronary atherosclerotic plaques in diabetes. Arterioscler Thromb Vasc Biol. 2004;24:1266-1271.

5. Cipollone F, Iezzi A, Fazia M, et al. The receptor RAGE as a progression factor amplifying arachidonate-dependent inflammatory and proteolytic response in human atherosclerotic plaques: role of glycemic control. Circulation. 2003;108: 1070-1077.

6. Brett J, Schmidt AM, Yan SD, et al. Survey of the distribution of a newly characterized receptor for advanced glycation endproducts in tissues. Am J Pathol. 1993;143:1699-1722.

7. Arumugam T, Simeone DM, Schmidt AM, Logsdon CD. S100P stimulates cell proliferation and survival via receptor for advanced glycation end products (RAGE). J Biol Chem. 2004;279:5059-5065.

8. Bucciarelli LG, Wendt T, Qu W, et al. RAGE blockade stabilizes established atherosclerosis in diabetic apolipoprotein E-null mice. Circulation. 2002;106: 2827-2835.

9. Park L, Raman KG, Lee KJ, et al. Suppression of accelerated diabetic atherosclerosis by the soluble receptor for advanced glycation endproducts. Nat Med. 1998;4:1025-1031.

10. Tekabe Y, Li Q, Rosario R, et al. Development of RAGE-directed imaging of atherosclerosis plaque in a murine model of spontaneous atherosclerosis. Circ Cardiovasc Imaging. 2008;1:212-219.

11. Liliensiek B, Weigand MA, Bierhaus A, et al. Receptor for advanced glycation endproducts (RAGE) regulates sepsis but not the adaptive immune response. J Clin Invest. 2004;113:1641-1650.

12. Candido R, Jandeleit-Dahm KA, Cao Z, et al. Prevention of accelerated atherosclerosis by angiotensin-converting enzyme inhibition in diabetic apolipoprotein E-deficient mice. Circulation. 2002;106:246-253.

13. Neeper M, Schmidt AM, Brett J, et al. Cloning and expression of RAGE: a cell surface receptor for advanced glycosylation endproducts of proteins. $J$ Biol Chem. 1992;267:14998-15004.

14. Hnatowich DJ, Layne WW, Childs RL, et al. Radioactive labeling of antibody: a simple and efficient method. Science. 1983;220:613-615.

15. Forrer F, Valkema R, Bernard B, et al. In vivo radionuclide uptake quantification using a multi-pinhole SPECT system to predict renal function in small animals. Eur J Nucl Med Mol Imaging. 2006;33:1214-1217.

16. Daugherty A, Whitman SC. Quantification of atherosclerosis in mice. In: Hofker MH, van Duersen J, eds. Transgenic Mouse Methods and Protocols. Totowa, NJ: Humana Press; 2003:293-307.

17. Tawakol A, Migrino RQ, Hoffmann U, et al. Noninvasive in vivo measurement of vascular inflammation with F-18 fluorodeoxyglucose positron emission tomography. J Nucl Cardiol. 2005;12:294-301.

18. Kolodgie FD, Petrov A, Virmani R, et al. Targeting of apoptotic macrophages and experimental atheroma. Circulation. 2003;108:3134-3139.

19. Schäfers M, Remann B, Kopha K, et al. Scintigraphic imaging of matrix metalloproteinase activity in the arterial wall in vivo. Circulation. 2004;109: 2554-2559. 